\title{
A High Efficiency Rare Earth-Free Orange Emitting Phosphor
}

\author{
E. Polikarpov, ${ }^{a}$ D. Catalini, ${ }^{a}$ A. Padmaperuma, ${ }^{a}$ P. Das,${ }^{c}$ T. Lemmon, ${ }^{a}$ B. Arey,${ }^{b}$ and C. A. Fernandez ${ }^{a^{*}}$
}

Received 00th January 2012,

Accepted 00th January 2012

DOI: $10.1039 / \times 0 \times x 00000 x$

*carlos.fernandez@pnnl.gov

This communication provides a brief summary on rare earth (RE)-based and RE free-based nitrides and oxynitride phosphors reporting for the first time the photoluminescence quantum yield (PLQY) of a highly emissive AIN: $\mathbf{M n}^{2+}$ obtained at relatively low temperatures. The PLQY of the AIN:Mn emitter was measured to be $82 \%$, a value among the highest measured for non-RE phosphors. . Though the AIN matrix shows an emission peak at a similar position to the emission peak observed for AIN:Mn product, the Mn-containing species generates orange emission by a different mechanism, which was supported by the emission life time studies and in accordance with previous reports on this material.

\section{Keywords}

Phosphor, rare-earth free, photoluminescence, quantum yield, aluminum nitride, manganese, efficiency

\section{Introduction}

Commercially available energy efficient lighting products (LED and Fluorescent) are based on down conversion of ultraviolet luminescence to visible by rare earth (RE)-based phosphors. RE concentration can be as high as $15 \%$ in current phosphors used in compact fluorescent lighting (CFL) and represents more than 50\% of total product cost.[1] High-efficiency fluorescent lighting represents approximately $85 \%$ of global demand for RE phosphors (a linear fluorescent lamp uses $\sim 5 \mathrm{~g}$ of rare-earth oxides per bulb).[2] Although LEDs can theoretically use smaller amounts of phosphors, the current products based on external phosphor layers have heavy dependence on the RE-based materials. Phosphors that do not include $\mathrm{RE}$ ions, such as $\mathrm{ZnO}, \mathrm{CdS}, \mathrm{CdSe}$, and $\mathrm{ZnS}: \mathrm{Mn}$, always contain toxic elements (Cd, S, and $\mathrm{Se}$ ) which have long-term adverse effects on the environment. SemiconductorToday predicts that packaged LEDs in general lighting to grow from $\$ 500 \mathrm{~m}$ (2010) to $\$ 13.4 \mathrm{bn}$ in 2020.[3] The market for compact fluorescent lamps (CFL) was estimated $\$ 1.6$ billion for 2010 and is expected to be worth nearly $\$ 20$ billion by 2015.[3] As lighting energy efficiency standards are implemented globally, heavy rare earths used in lighting phosphors may be in short supply. In the United States, two sets of lighting energy efficiency standards took effect in 2012 leading to an increase in demand for fluorescent lamps containing phosphors made with europium, terbium and yttrium. Therefore, the replacement of down conversion REbased phosphors will reduce the market demand and US dependence on foreign sources, decrease environmental impact, and promote new industry development in the US.

Nitrides and oxynitrides have attracted significant attention in recent years because of their remarkable (thermal and chemical) stability, good fracture toughness while exhibiting unusual PL under nearultraviolet or blue-light irradiation when activated with RE ions.[4-6] Examples of these materials are $\mathrm{M}_{2} \mathrm{Si}_{5} \mathrm{~N}_{8}: \mathrm{Eu}^{2+}, \mathrm{Ce}^{3+} ;[7-12] \mathrm{MSi}_{2} \mathrm{O}_{2-\delta} \mathrm{N}_{2+2} / 3 \delta: \mathrm{Eu}^{2+}, \mathrm{Ce}^{3+}(\mathrm{M}=\mathrm{Ca}, \mathrm{Sr}, \mathrm{Ba}) ;[8,11] \mathrm{MSiN}_{2}: \mathrm{Eu}^{2+}, \mathrm{Ce}^{3+}(\mathrm{M}=\mathrm{Ca}$, $\mathrm{Sr}, \mathrm{Ba}) ;[12,13] \mathrm{MgSiN}_{2}: \mathrm{Eu}^{2+} ;[14,15] \mathrm{MYSi}_{4} \mathrm{~N}_{7}: \mathrm{Eu}^{2+}, \mathrm{Ce}^{3+}(\mathrm{M}=\mathrm{Sr}, \mathrm{Ba}) ;[16,17] \mathrm{MSi}_{\mathrm{x}} \mathrm{Al}_{2-\mathrm{x}} \mathrm{O}_{4-\mathrm{x}} \mathrm{N}_{\mathrm{x}}: \mathrm{Eu}^{2+}(\mathrm{M}$ $=\mathrm{Ca}, \mathrm{Sr}, \mathrm{Ba}) ;[18] \alpha-\mathrm{SiAlON}: \mathrm{RE}\left(\mathrm{RE}=\mathrm{Eu}^{2+}, \mathrm{Ce}^{3+,} \mathrm{Yb}^{2+}, \mathrm{Tb}^{3+,} \mathrm{Pr}^{3+}, \mathrm{Sm}^{3+}\right) ;[19-25] \beta-\mathrm{SiAlON}: \mathrm{Eu}^{2+} ;[26]$ and $\mathrm{CaAlSiN}_{3}: \mathrm{Eu}^{2+}$.[27-29] As for the application of $\mathrm{Mn}^{2+}$-doped phosphors in the field of wLED, many studies have been performed. A good number of these studies have been focused on $\mathrm{Eu}^{2+}-$ and $\mathrm{Mn}^{2+}-\mathrm{co}^{-}$ 
activated materials, such as $\mathrm{Ba}_{3} \mathrm{MgSi}_{2} \mathrm{O}_{8}: \mathrm{Eu}^{2+}, \mathrm{Mn}^{2+} ; \mathrm{CaAl}_{2} \mathrm{Si}_{2} \mathrm{O}_{8}: \mathrm{Eu}^{2+}, \mathrm{Mn}^{2+} ; \mathrm{SrZn}_{2}\left(\mathrm{PO}_{4}\right)_{2}: \mathrm{Eu}^{2+}, \mathrm{Mn}^{2+}$; $\mathrm{La}_{0.827} \mathrm{Al}_{11.9} \mathrm{O}_{19.09}: \mathrm{Eu}^{2+}, \mathrm{Mn}^{2+}$ and so on.[30-32] In these $\mathrm{Eu}^{2+}-$ and $\mathrm{Mn}^{2+}$-co-activated materials strong green, yellow and /or red emission of $\mathrm{Mn}^{2+}$ was obtained besides the blue emission of $\mathrm{Eu}^{2+}$ due to the strong absorption of $\mathrm{Eu}^{2+}$ in the wavelength range of 250-400 $\mathrm{nm}$ and efficient energy transfer from $\mathrm{Eu}^{2+}$ to $\mathrm{Mn}^{2+} .[30-32]$ Nevertheless, a handful of nitride-based phosphor materials where $\mathrm{Mn}$ is the only dopant have been reported by Hintzen et al.[33-35] For example, $\mathrm{Mn}^{2+}$-activated $\mathrm{M}_{2} \mathrm{Si}_{5} \mathrm{~N}_{8}(\mathrm{M}=\mathrm{Ca}, \mathrm{Sr}, \mathrm{Ba})$ phosphors were reported exhibiting emission bands with maxima at 567, 599 and $606 \mathrm{~nm}$ for $\mathrm{M}=\mathrm{Ba}$, Ca, Sr showing narrow emission as compared to red $\mathrm{Eu}^{2+}$ emission in these host-lattices[33]. CaAlSiN ${ }_{3}: \mathrm{Mn}^{2+}$ was reported by the same group exhibiting a broad band emission in the wavelength range of 475-750 nm originated from the overlapping emission bands of two different $\mathrm{Mn}$ sources, one located in the Ca site and another one in the Al site.[35] The quantum efficiencies of these materials were not reported but predicted to be lower than commercial phosphors. [33-35]

There have been a number of reports on RE-free phosphors with high photoluminescence quantum yields (PLQY) proving that RE-free phosphors are prospective candidates for replacing RE-based phosphors in lighting or display applications. $\mathrm{Ca}_{5}\left(\mathrm{PO}_{4}\right)_{3}(\mathrm{Cl}, \mathrm{F}): \mathrm{Sb}, \mathrm{Mn}$ phosphors have been known since 1960's to have high quantum yields, and were the basis of for the fluorescent lighting industry up until the 1990's[36] .Furthermore, Mn-containing non-RE high-efficiency phosphors $\mathrm{Zn} 2 \mathrm{SiO} 4: \mathrm{Mn}$ and $\mathrm{K}_{2} \mathrm{SiF}_{6}: \mathrm{Mn}$ have been synthesized.[37-39] Other examples of non-RE phosphors include $\mathrm{Zn}_{3} \mathrm{~V}_{2} \mathrm{O}_{8}$, which was synthesized by Luitel et al and showed a broadband yellowish white emission with a PLQY of $60 \%$ when excited with $260 \mathrm{~nm}$ light.[40] Another example is the yellow-green emitting $\mathrm{NaZnPO}_{4}: \mathrm{Mn}$ phosphor doped with 12 mol\% Mn which exhibited a $63 \%$ PLQY when excited at 418 nm.[41] A titanium-included silicate, $\mathrm{BaZr}_{0.99} \mathrm{Ti}_{0.01} \mathrm{Si}_{3} \mathrm{O}_{9}$, exhibited the highest quantum yield in the titanosilicate mineral family with $72 \%$ PLQY blue emission when excited at $230 \mathrm{~nm}$.[42]RE-free boron carbon oxynitride (BCNO) phosphors have also shown to be promising down-converter materials with reported color tunability and PLQY from 10\% for emission in the yellow (@571 nm) to $79 \%$ for emission in the blue (@469 nm).[42] Nevertheless, there is still some way to go to achieve PL efficiencies comparable to RE-based emitting materials, in particular the yellow emission of YAG:Ce standard phosphor (PLQY $=90 \%$ ).[43]

AlN-based emitters are very promising materials for light emitting diodes and electroluminescence devices, because their high thermal, chemical and mechanical stability, high thermal conductivity and because AlN has a wide bandgap (6.2 eV).[44-48] Recently, AlN:Eu ${ }^{2+}$ phosphor was reported for utilization in FEDs.[47] The AlN-based phosphors have good physical and chemical, wide bandgap, and meet the requirements of afterglow phosphors due to their high luminescence intensity. Therefore, it might be possible to develop $\mathrm{Mn}^{2+}$ doped AlN phosphor for lighting and displays applications, particularly if the emitting wavelength is in the orange-red part of the visible spectrum. Indeed, an AlN:Mn phosphor was reported exhibiting cathodoluminescence and photoluminescence as well as long lasting phosphorescence in the red.[49, 50] The materials, which were synthesized at 1900 and $1750{ }^{\circ} \mathrm{C}$ contained $1 \mathrm{~mol} \%$ and $2.5 \mathrm{~mol} \%$ of Mn, respectively and showed a strong red emission upon irradiation with $254 \mathrm{~nm}$ UV light. Nevertheless, no report on the PLQY is available in this very promising phosphor material. We report the synthesis of AlN:Mn RE-free phosphor at a lower temperature and measure for the first time the phosphor PLQY which turn out to be one of the highest photoluminescence quantum yield (PLQY) reported on a RE-free phosphor material.

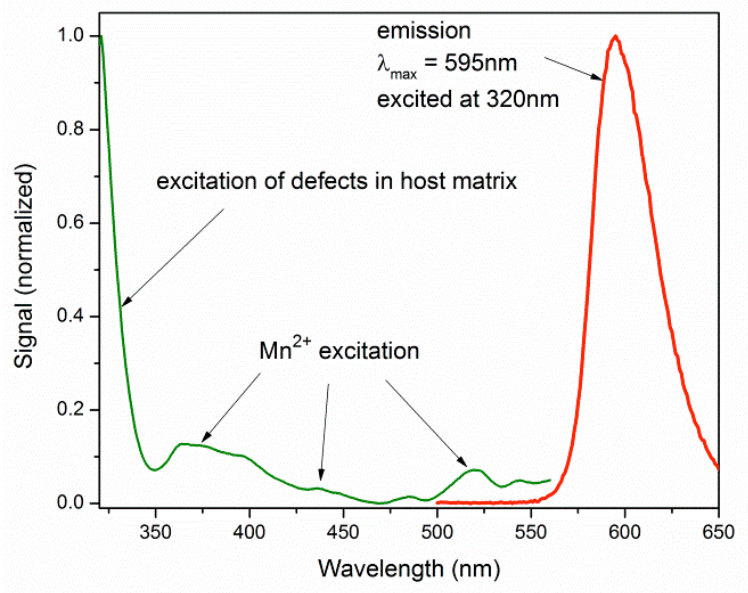

Figure 1. Normalized emission and excitation spectra of AlN:Mn. Excitation was monitored at $595 \mathrm{~nm}$. 


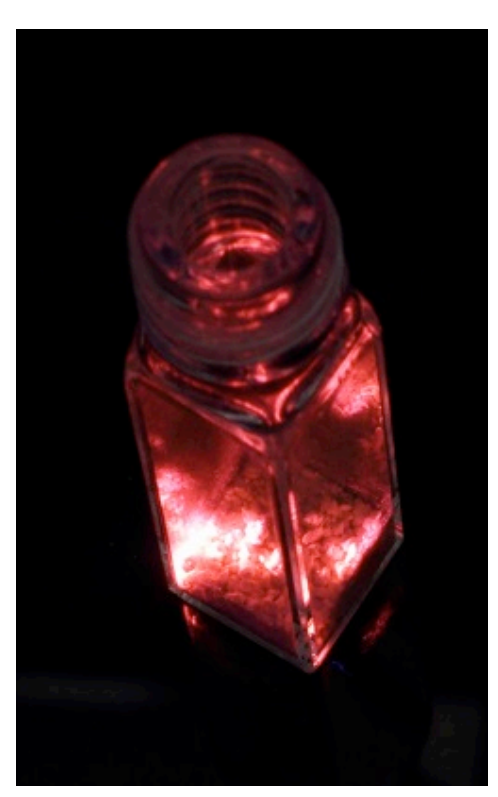

\section{Results}

Aluminum nitride with different molar percentages of Manganese AlN:xMn ( $\mathrm{x}=0.5,1,2,5$ and $10 \mathrm{~mol} \%)$ powder phosphors were prepared by weighing, mixing, and grinding appropriate amounts of the precursor materials in an agate mortar by hand under an air/moisture free atmosphere. Subsequently, the homogeneous powder mixtures were transferred to a Molybdenum crucible and calcined at different temperatures for $5 \mathrm{~h}$ in a 90/10 $\mathrm{N}_{2} / \mathrm{H}_{2}$ gas mixture. After firing, the samples were cooled to room temperature (RT) in the furnace and characterized by powder X-ray diffraction (pXRD), scanning electron microscopy coupled to energy dispersive scattering analysis (SEM/EDS), inductive coupling plasma mass spectrometry (ICP-MS) and absorption as well as photoluminescence spectroscopy.

Powder XRD studies on AIN and AlN:Mn samples show that the main component of the AlN:Mn phosphors is AlN hexagonal Wurzite phase (Figure $\mathrm{S} 1$ in supporting information). SEM/EDS analysis on AIN samples with and without manganese were performed to learn about the

Figure 2. AlN:Mn $1 \mathrm{~mol} \%$ orange emission when exposed to near UV $(250 \mathrm{~nm})$ excitation light. main elements present in the material that can't be identified by ICPMS, i.e., nitrogen and potentially oxygen. Figure S2 shows a scanning electron micrograph of AlN and AlN:Mn 1mol\% while Figure S3 shows the EDS spectra of both Mn-doped and undoped AIN samples where the presence of aluminum, nitrogen, and oxygen is observed. It has been reported that the presence of oxygen in the samples is critical to the optical properties of these materials and it will be discussed later. One surprising finding was the absence of manganese in the EDS spectrum of the AlN:Mn doped samples. This may be due to the relatively low concentrations of the dopant as compared to the host matrix. Although the precense of manganese was not observed by either EDS or XRD analysis, ICP-MS performed on samples prepared with different Mn content showed in all cases a concentration of $\mathrm{Mn}$ that ranged between 1.06 and $1.27 \mathrm{~mol} \%$ independently of the manganese starting concentration. This could be an indication that at these temperatures there is loss of excess manganese by sublimation even though the crucibles were tightly sealed. For example, increasing the reaction temperature from $1500{ }^{\circ} \mathrm{C}$ to $1800{ }^{\circ} \mathrm{C}$ obtained emissive samples with the same manganese content range while decreasing the reaction temperature to minimize manganese sublimation resulted in non- emissive samples as described later. The photoluminescence emission and excitation spectra of the AlN: Mn $1.06 \mathrm{~mol} \% \mathrm{Mn}$ (from now on $1 \mathrm{~mol} \%$ ) at $1500{ }^{\circ} \mathrm{C}$ under $\mathrm{N}_{2}$ atmosphere are depicted in Figure 1. The reaction product of AlN with $\mathrm{Mn}$ at $1500^{\circ} \mathrm{C}$ emits bright orange light with a peak maximum at around $595 \mathrm{~nm}$ when excitetd by UV radiation (Figure 2). The part of excitation spectrum monitored at $595 \mathrm{~nm}$ shown in Figure 1 contains features characteristic of presence of $\mathrm{Mn}^{2+}$ species in the samples,[13] though these features are very weak since the transitions are spin and parity forbidden.

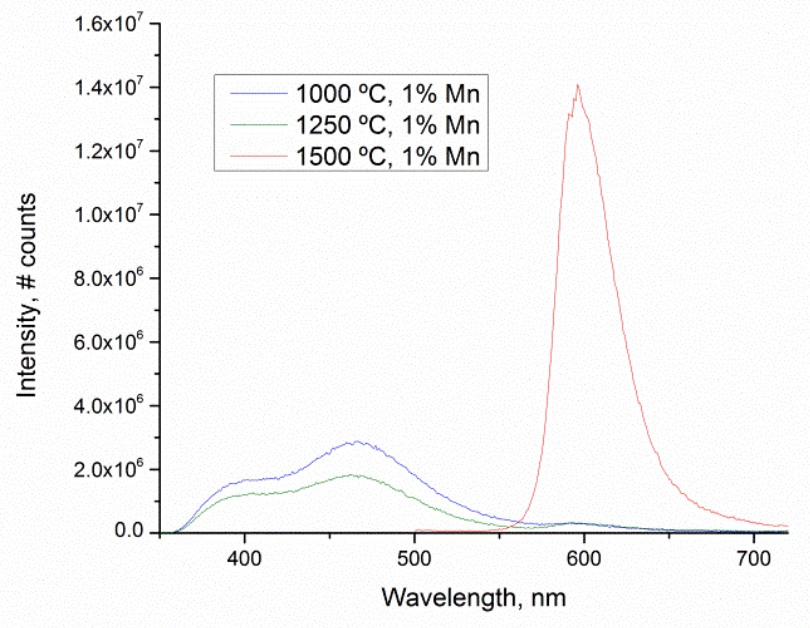

Figure 3. Dependence of the PL spectra of the products of the reaction between $\mathrm{AlN}$ and $\mathrm{Mn}$ on the process temperature. 


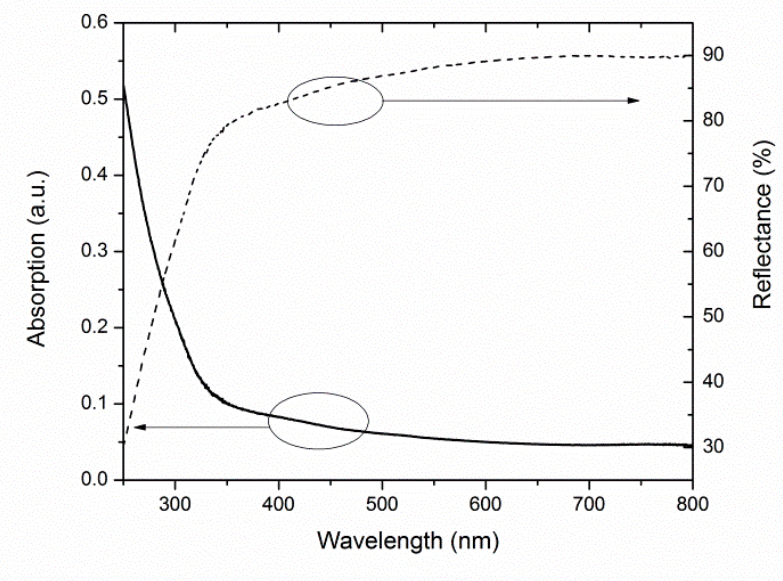

Figure 4. Measured total reflection (dotted line) and absorption (solid line) calculated from the reflection spectrum of the reaction product of $\mathrm{Mn}$ with $\mathrm{AlN}$ at $1500^{\circ} \mathrm{C}$.
The reaction temperature was optimized by monitoring the PL emission of the fired mixtures. It was found that below $1500^{\circ} \mathrm{C}$ the precursors do not interact sufficiently to produce the orange-emitting species. For those lowtemperature reaction products only the matrix emittion was detected. The lack of emission for the low temperature reaction (Figure 3) is probably due to the absense of $\mathrm{Mn}^{2+}$, whereas all the $\mathrm{Mn}$ is still in the metallic form at those temperatures which is possible to see with the neaked eye. Nevertheless, XRD analysis of the products obtained at 1000 and $1250{ }^{\circ} \mathrm{C}$ also show that the main component of the materials is AlN hexagonal Wurzite phase.

Figure 4 shows the total reflectance and absorption of AlN:Mn calculated from the reflection spectrum of the reaction product of $\mathrm{Mn}$ with $\mathrm{AlN}$ at $1500^{\circ} \mathrm{C}$. The main feature in the absorption spectrum in Figure 4 closely follows the excitation spectrum pattern when the emission is monitored at $595 \mathrm{~nm}$, in accordance with previous reports. $[49,50]$ This high intensity UV absorption band with the onset at below 330nm originates from the AlN matrix. The small features in the 350-500nm region that originate from $\mathrm{Mn}^{2+}$ and that are visible in the excitation spectrum in Figure 1 are too weak to be detectable in the reflection spectra (data not shown).

The normalized emission spectra of the AlN matrix and AlN:Mn emitter are superimposed in Figure 5. As seen from Figure 5, the host matrix exhibits a weak feature in the $600 \mathrm{~nm}$ area which overlaps with the AlN:Mn main peak. This observation could suggest that the role of $\mathrm{Mn}$ is to enhance the emission that originates from the matrix. Lifetime analysis on the emission of AlN and AlN:Mn 1mol\% were performed to verify this hypothesis. However, the emission life time analysis eliminates the possibility of Mn enhancing AlN host emission and proves that the positions of the AlN:Mn emission maximum and the secondary peak in the matrix spectrum are merely coinsidental. The life time of the AlN:Mn emission peak at $595 \mathrm{~nm}$ is 1.6 milliseconds, which is close to the characteristic signal of $\mathrm{Mn}^{2+}$, whereas the emission from the neat AlN host at similar wavelength was measured to be 1.6 microseconds. The origin of the strong emission line in the region around $600 \mathrm{~nm}$ in $\mathrm{AlN}: \mathrm{Mn}$ is the $\mathrm{Mn}^{2+} 4 \mathrm{~T} 1(4 \mathrm{G})-6 \mathrm{~A} 1(6 \mathrm{~S})$ transition.[50, 51] It has been pointed out that oxygen-related defects may play an important role in generating orange-red emission.[52, 53] Specifically, the $\mathrm{O}_{\mathrm{N}}-\mathrm{V}_{\mathrm{Al}}$ defect states excited by the UV radiation will efficiently energy transfer onto the lowest excited state of $\mathrm{Mn}^{2+}$ which subsequently emits orange light. According to Berzina et al., the strong excitation band at $250 \mathrm{~nm}$, tail of which can be seen in Figure 1, can be ascribed to the excitation of the $\mathrm{O}_{\mathrm{N}}-\mathrm{V}_{\mathrm{Al}}$ complex.[50, 53] Also characteristic of the presence of defect states is the afterglow effect in AlN:Mn that is observed after removing the excitation source in accordance with previous reports. $[49,50]$

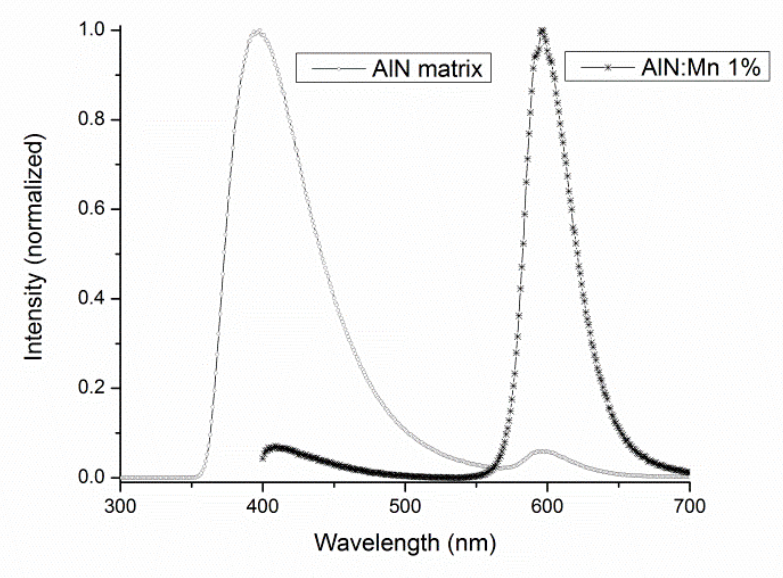

Figure 5. Normalized emission spectra of the AlN matrix and AlN:Mn emitter powders. 
Figures 1 and 2 suggest that the emission intensity of the Mn-doped AlN can be significantly higher than that of the neat matrix. The PLQY of AIN:Mn 1mol\% was measured using a Horiba Scientific Fluoromax-4C spectrofluorometer equipped with Horiba Quanta-Phi PLQY Integrating Sphere. The excitation wavelength was chosen to be $320 \mathrm{~nm}$ and the emission collected emission at $595 \mathrm{~nm}$. Indeed, the PLQY of AlN:Mn was 82\%, a value among the highest measured for non-RE phosphors reported so far.

\title{
Conclusions
}

In summary, this work introduces a brief review in RE-based and RE free-based nitrides and oxynitride phosphors with emphasis on the advantages of Mn-based nitrides. In particular, the recently reported AlN: $\mathrm{Mn}^{2+}$ emitter was synthesized at lower temperatures and its PLQY measured to be $82 \%$. The results demonstrate that RE-free phosphors represent a tangible alternative for lighting applications to current $\mathrm{RE}$ phosphors based on $\mathrm{Eu}^{2+}$ and $\mathrm{Tb}^{3+}$ dopants.

\author{
Notes and references \\ ${ }^{a}$ Energy and Environment Directorate, Pacific Northwest National Laboratory, P. O. Box 999, \\ Richland, WA 99352 \\ ${ }^{b}$ Environmental and Molecular Science Laboratory, Pacific Northwest National Laboratory, P. O. \\ Box 999, Richland, WA 99352 \\ ${ }^{c}$ Center for Renewable Carbon, University of Tennessee
}

$\dagger$ The authors would like to acknowledge Matthew Love and Walter Weimer for the encouragement and support and the Laboratory Directed Research Development program from Pacific Northwest National Laboratory (PNNL) for the financial support (LDRD/65140). SEM and EDS analysis was performed in EMSL (Environmental Molecular Sciences Laboratory; EMSL proposal \# 48166), a DOE national scientific user facility at Pacific Northwest National Laboratory (PNNL).

Electronic Supplementary Information (ESI) available: [Materials and Methods including characterization of the phosphor materials including SEM, EDS, ICP-MS, XRD and PLQY are described in detail in the supporting information]. See DOI: 10.1039/c000000x/

[1] According to a statement from Ellis Yan, CEO of TCP Inc. "Where phosphor once represented roughly $10 \%$ to $15 \%$ of the cost of a typical CFL, it can now exceed $50 \%$ (or more in some models) of the total lamps production cost".

[2] Chu S. Critical Materials Strategy. 2011.p. 166 pages.

[3] http://www.semiconductor-today.com/news items/2011/MAY/ELECTRONI 230511.html.

[4] Dickerson JH, Boccaccini AR. Electrophoretic Deposition of Nanomaterials: Springer; 2012.

[5] Ohashi Y, Motohashi T, Masubuchi Y, Kikkawa S. Crystal structure and superconductive characteristics of Nb0.89A10.11 oxynitrides. Journal of Solid State Chemistry 2010;183:1710-4.

[6] Xie R-J, Hirosaki N, Mitomo M. Oxynitride/nitride phosphors for white light-emitting diodes (LEDs). Journal of Electroceramics 2008;21:370-3.

[7] Bachmann V, Jüstel T, Meijerink A, Ronda C, Schmidt PJ. Luminescence properties of SrSi2O2N2 doped with divalent rare earth ions. Journal of Luminescence 2006;121:441-9.

[8] Li YQ, de With G, Hintzen HT. Luminescence of a new class of UV-blue-emitting phosphors MSi2O2-

$\delta \mathrm{N} 2+2 / 3 \delta: \mathrm{Ce} 3+(\mathrm{M}=\mathrm{Ca}, \mathrm{Sr}, \mathrm{Ba})$. Journal of Materials Chemistry 2005;15:4492-6.

[9] Li YQ, de With G, Hintzen HT. Luminescence properties of Ce3+-activated alkaline earth silicon nitride M2Si5N8 (M=Ca, Sr, Ba) materials. Journal of Luminescence 2006;116:107-16.

[10] Li YQ, Delsing ACA, de With G, Hintzen HT. Luminescence Properties of Eu2+-Activated Alkaline-Earth Silicon-Oxynitride MSi2O2- $\delta \mathrm{N} 2+2 / 3 \delta(\mathrm{M}=\mathrm{Ca}, \mathrm{Sr}, \mathrm{Ba})$ : A Promising Class of Novel LED Conversion Phosphors. Chemistry of Materials 2005;17:3242-8.

[11] Piao X, Horikawa T, Hanzawa H, Machida K-i. Characterization and luminescence properties of Sr2Si5N8:Eu2+ phosphor for white light-emitting-diode illumination. Applied Physics Letters 2006;88:-

[12] Xie R-J, Hirosaki N, Suehiro T, Xu F-F, Mitomo M. A Simple, Efficient Synthetic Route to Sr2Si5N8:Eu2+Based Red Phosphors for White Light-Emitting Diodes. Chemistry of Materials 2006;18:5578-83. 
[13] Duan CJ, Wang XJ, Otten WM, Delsing ACA, Zhao JT, Hintzen HT. Preparation, Electronic Structure, and Photoluminescence Properties of Eu2+- and Ce3+/Li+-Activated Alkaline Earth Silicon Nitride MSiN2 (M = Sr, Ba). Chemistry of Materials 2008;20:1597-605.

[14] Dubrovskii GP, Zykov AM, Chernovets BV. Luminescence of MgSiN//2 Activated with Rare Earth Elements. Neorganiceskie materialy 1981;17:1421-5.

[15] Gaido GK, Dubrovskii GP, Zykov AM. Photoluminescence of MgSiN2 activated by europeum. Neorganiceskie materialy 1974;10:564-6.

[16] Li YQ, de With G, Hintzen HT. Synthesis, structure, and luminescence properties of Eu2+ and Ce3+ activated BaYSi4N7. Journal of Alloys and Compounds 2004;385:1-11.

[17] Li YQ, Fang CM, de With G, Hintzen HT. Preparation, structure and photoluminescence properties of Eu2+ and Ce3+-doped SrYSi4N7. Journal of Solid State Chemistry 2004;177:4687-94.

[18] Li YQ, de With G, Hintzen HT. Luminescence Properties of Eu2 +-Doped MA12 - x Si x O4 - x N x ( $\mathrm{M}=\mathrm{Ca}, \mathrm{Sr}, \mathrm{Ba})$ Conversion Phosphor for White LED Applications. Journal of The Electrochemical Society 2006;153:G278-G82.

[19] Xie R-J, Mitomo M, Uheda K, Xu F-F, Akimune Y. Preparation and Luminescence Spectra of Calcium- and Rare-Earth ( $\mathrm{R}=\mathrm{Eu}, \mathrm{Tb}$, and Pr)-Codoped a-SiAlON Ceramics. Journal of the American Ceramic Society 2002;85:1229-34.

[20] Xie R-J, Hirosaki N, Mitomo M, Yamamoto Y, Suehiro T, Sakuma K. Optical Properties of Eu2+ in a-SiAlON. The Journal of Physical Chemistry B 2004;108:12027-31.

[21] Xie R-J, Hirosaki N, Sakuma K, Yamamoto Y, Mitomo M. Eu ${ }^{2+}$-doped Ca- $\alpha$-SiAlON: A yellow phosphor for white light-emitting diodes. Applied Physics Letters 2004;84:5404-6.

[22] Xie RJ, Hirosaki N, Mitomo M, Uheda K, Suehiro T, Xu X, et al. Strong Green Emission from a-SiAlON Activated by Divalent Ytterbium under Blue Light Irradiation. The Journal of Physical Chemistry B 2005;109:94904.

[23] Xie R-J, Hirosaki N, Mitomo M, Takahashi K, Sakuma K. Highly efficient white-light-emitting diodes fabricated with short-wavelength yellow oxynitride phosphors. Applied Physics Letters 2006;88:101104--3. [24] Krevel JWHv, Rutten JWTv, Mandal H, Hintzen HT, Metselaar R. Luminescence Properties of Terbium-, Cerium-, or Europium-Doped a-Sialon Materials. Journal of Solid State Chemistry 2002;165:19-24.

[25] Xie R-J, Hirosaki N, Mitomo M, Sakuma K, Kimura N. Wavelength-tunable and thermally stable Li- $\alpha$-sialon $\mathrm{Eu}^{2+}$ oxynitride phosphors for white light-emitting diodes. Applied Physics Letters 2006;89:241103--3.

[26] Hirosaki N, Xie R-J, Kimoto K, Sekiguchi T, Yamamoto Y, Suehiro T, et al. Characterization and properties of green-emitting $\alpha$-SiAlON:Eu ${ }^{2+}$ powder phosphors for white light-emitting diodes. Applied Physics Letters 2005;86:211905--3.

[27] Li J, Watanabe T, Wada H, Setoyama T, Yoshimura M. Low-Temperature Crystallization of Eu-Doped RedEmitting CaAlSiN3 from Alloy-Derived Ammonometallates. Chemistry of Materials 2007;19:3592-4.

[28] Piao X, Machida K-i, Horikawa T, Hanzawa H, Shimomura Y, Kijima N. Preparation of CaAlSiN3:Eu2+ Phosphors by the Self-Propagating High-Temperature Synthesis and Their Luminescent Properties. Chemistry of Materials 2007;19:4592-9.

[29] Uheda K, Hirosaki N, Yamamoto Y, Naito A, Nakajima T, Yamamoto H. Luminescence Properties of a Red Phosphor, CaAlSiN3 : Eu2 + , for White Light-Emitting Diodes. Electrochemical and Solid-State Letters 2006;9:H22-H5.

[30] Li Y, He D, Yongsheng W, Fu M, Wu Y, Miao F. Luminescence Properties of Nano-Crystalline $\mathrm{Ba}_{3} \mathrm{MgSi}_{2} \mathrm{O}_{8}: \mathrm{Eu}^{2+}, \mathrm{Mn}^{2+}$ Phosphors. Journal of Nanoscience and Nanotechnology 2011;11:9829-32.

[31] Wang B, Sun L, Ju H, Zhao S, Deng D, Wang H, et al. Single-phased white-light emitting CaA12Si2O8: Eu2+, Mn2+ phosphors prepared by a sol-gel method. Journal of Sol-Gel Science and Technology 2009;50:368-71.

[32] Yi L, Zhou L, Gong F, Lan Y, Tong Z, Sun J. Preparation of SrZn2(PO4)2:Eu2+,Mn2+ phosphor and its photoluminescent properties. Materials Science and Engineering: B 2010;172:132-5.

[33] Duan CJ, Delsing ACA, Hintzen HT. Journal ofLuminescence 2009;129:645-9

[34] Duan CJ, Otten WM, Delsing ACA, Hintzen HT. Journal of Solid State Chemistry 2008;181:751-7.

[35] Zhang Z, Delsing ACA, Notten PHL, Zhao J, Dorenbos P, Hintzen HT. ECS Journal of Solid State Science and Technology 2013;2:R70-R5.

[36] Ishler WE, Apple EF. Improving the performance of calcium halophosphate phosphors. 1964.

[37] Cho JS, Lee SM, Jung KY, Chan Kang Y. Large-scale production of fine-sized Zn2SiO4:Mn phosphor

microspheres with a dense structure and good photoluminescence properties by a spray-drying process. RSC Advances 2014;4:43606-11.

[38] Sivakumar V, Lakshmanan A. Pyrolysis synthesis of Zn2SiO4:Mn2+ phosphors - effect of fuel, flux and codopants Journal of Luminescence 2014;145:420-4.

[39] Setlur A. Optimized Phosphors for Warm White LED Light Engines. 2013, pp 1-49.

[40] Luitel HNC, R.; Torikai, T.; Yada, M.; Watari, T. International Journal of Photoenergy

2013:1-9. 
[41] Haranath DM, S.; Yadav, S.; Sharma, R. K.; Kandpal, L. M.; Vijayan, N.; Dalai, M. K.; Sehgal, G.; Shanker, V. . Applied Physics Letters

2012;101:1-5.

[42] Wang W-N, Ogi T, Kaihatsu Y, Iskandarc F, Okuyama K. Journal of Materials Chemistry

2011;21:5138-89.

[43] Denault KAC, M.; Nakamura, S.; DenBaars, S. P.; Seshadri, R. . AIP Advances 2013 3:1-6.

[44] Gruber JB, Burdick GW, Vetter U, Mitchell B, Dierolf V, Hofsäss H. Crystal field and Zeeman splittings for energy levels of Nd3+ in hexagonal AIN. Optical Materials Express 2012;2:1176-85.

[45] Hirosaki N, Xie R-J, Inoue K, Sekiguchi T, Dierre B, Tamura K. Blue-emitting AlN:Eu2+ nitride phosphor for field emission displays. Applied Physics Letters 2007;91:-.

[46] Liu T-C, Kominami H, Greer HF, Zhou W, Nakanishi Y, Liu R-S. Blue Emission by Interstitial Site Occupation of Ce3+ in AlN. Chemistry of Materials 2012;24:3486-92.

[47] Won Y-H, Jang HS, Im WB, Jeon DY, Lee JS. Tunable full-color-emitting La0.827Al11.9O19.09:Eu2+,Mn2+ phosphor for application to warm white-light-emitting diodes. Applied Physics Letters 2006;89:-

[48] Yin L-J, Zhu Q-Q, Yu W, Hao L-Y, Xu X, Hu F-C, et al. Europium location in the AlN: Eu green phosphor prepared by a gas-reduction-nitridation route. Journal of Applied Physics 2012;111:-.

[49] Zhang H, Zheng M, Lei B, Liu Y, Xiao Y, Dong H, et al. ECS Journal of Solid State Science and Technology 2013;2:R117-R20.

[50] Wang X-J, Xie R-J, Dierre B, Takeda T, Suehiro T, Hirosaki N, et al. Dalton Transactions 2014;443:6120-7.

[51] Shang MML, G. G.; Yang, D. M.; Kang, X. J.; Peng, C., Lin J. Dalton Transactions 2012;41:8861-8.

[52] Shi SC, C.; Chattopadhyay, S.; Chen, K.; Trinkler, L.; Berzina, B. . Appl Phys Lett

2006;89:1-4.

[53] Schweizer SR, U.; Spaeth, J. M.; Trinkler, L.; Berzina, B. Phys Status Solidi B 2000;219:171-80. 


\section{Graphical Abstract}
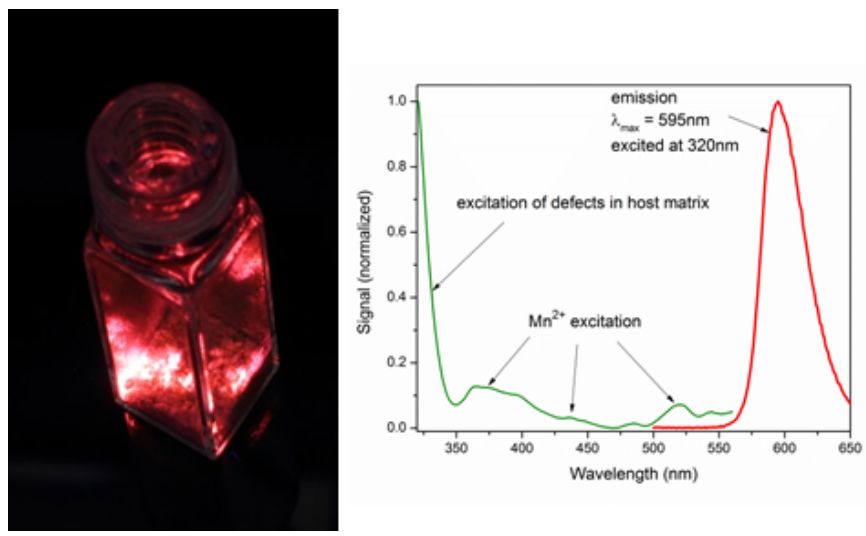

A highly efficient (PLQY=82\%) orange emitting RE-free phosphor synthesized with inexpensive precursors at relatively low $\mathrm{T}$. 